\title{
O ENSINO DE SEQUÊNCIAS NUMÉRICAS POR MEIO DOS NÚMEROS TRIANGULARES UTILIZANDO A HISTÓRIA DA MATEMÁTICA
}

\section{THE TEACHING OF NUMERICAL SEQUENCES THROUGH TRIANGULAR NUMBERS USING THE HISTORY OF MATHEMATICS}

\author{
Thalya Cristiny De Sousa Masseno ${ }^{1}$ \\ EEEP Professor Francisco Aristóteles de Sousa \\ Ana Carolina Costa Pereira ${ }^{2}$ \\ Universidade Estadual do Ceará (UECE)
}

\begin{abstract}
Resumo
Este estudo, é uma proposta de atividades didáticas envolvendo o conteúdo de sequências numéricas por meio dos números triangulares, partindo do estudo documental de pesquisas já realizadas sobre o tema. A sequência numérica é um assunto que muitos alunos têm dificuldade, principalmente porque eles não conseguirem enxergar o infinito, muito menos, a soma de elementos infinitas vezes. Por esse motivo, esta pesquisa foi desenvolvida para o professor ter um novo apoio pedagógico, tendo como objetivo conhecer as contribuições dos números triangulares para o estudo de sequências numéricas por meio de atividades didática no ensino médio. Através de atividades que utilizam a história da matemática e material manipulável no estudo dos números triangulares. Para produção deste estudo, foram utilizados a pesquisa documental e bibliográfica, pois analisamos estudos sobre os números triangulares. Dentre elas, estavam a história da matemática, os conceitos matemáticos dos números triangulares, e as que trabalhavam com materiais manipuláveis. Portanto, foram elaboradas atividades, que auxiliarão os professores no ensino de sequência numérica. Podendo ser realizadas com a sequência didática ou com as atividades orientadoras de estudos.
\end{abstract}

Palavras-chave: Números Triangulares. História da Matemática. Material Manipulável.

\begin{abstract}
\footnotetext{
1 thaliacristiny97@gmail.com

${ }^{2}$ Endereço eletrônico: alinhado à esquerda.
}

This study is a proposal of didactic activities involving the content of numerical sequences through triangular numbers, starting from the documentary study of research already conducted on the subject. The numerical sequence is a subject that many students have difficulty, mainly because they cannot see the infinite, much less, the sum of elements infinitetimes. For this reason, this research was developed for the teacher to have a new pedagogical support, aiming to know the contributions of triangular numbers to the study of numerical sequences through didactic activities in high school. Through activities that use the history of mathematics and manipulated material in the study of triangular 
numbers. For the production of this study, documentary and bibliographic research was used, because we analyzed studies on triangular numbers. Among them were the history of mathematics, the mathematical concepts of triangular numbers, and those who worked with manipulated materials. Therefore, activities have been elaborated, which will assist teachers in numerical sequence teaching. It can be performed with the didactic sequence or with the guiding activities of studies.

Keywords: Triangular Numbers. History of Mathematics. Manipulable material.

\section{Introdução}

Dentre os vários conteúdos que merecem atenção na educação básica, em particular no ensino médio, estão as sequências numéricas, em especial as progressões aritméticas e geométricas. Essa atenção pode ser percebida por meio dos guias curriculares nacionais, tais como os Parâmetros Curriculares Nacionais (PCN) e a Base Nacional Curricular Comum (BNCC), no qual as relaciona com as funções afim e exponencial, no campo dos números naturais. Isso é percebido em Brasil (2002, p. 121):

Com relação às sequências, é preciso garantir uma abordagem conectada à ideia de função, na qual as relações com diferentes funções possam ser analisadas. $\mathrm{O}$ estudo da progressão geométrica infinita com razão positiva e menor que 1 oferece talvez a única oportunidade de o aluno estender o conceito de soma para um número infinito de parcelas, ampliando sua compreensão sobre a adição e tendo a oportunidade de se defrontar com as ideias de convergência e de infinito.

Essas ideias também estão presentes no ensino de sequencias numéricas orientada pelos documentos oficiais também estão destacadas na Competência Específica $5^{3}$, voltada para o ensino médio na disciplina de matemática, encontramos a habilidade aa seguir:

(EM13MAT507) Identificar e associar progressões aritméticas (PA) a funções afins de domínios discretos, para análise de propriedades, dedução de algumas fórmulas e resolução de problemas.

(EM13MAT508) Identificar e associar progressões geométricas (PG) a funções exponenciais de domínios discretos, para análise de propriedades, dedução de algumas fórmulas e resolução de problemas.

\footnotetext{
${ }^{3}$ Competência Específica 5: Investigar e estabelecer conjecturas a respeito de diferentes conceitos e propriedades matemáticas, empregando estratégias e recursos, como observação de padrões, experimentações e diferentes tecnologias, identificando a necessidade, ou não, de uma demonstração cada vez mais formal na validação das referidas conjecturas (2018, p. 532)
} 
Percebam que a BNCC dá ênfase na dedução de algumas fórmulas e na resolução de problemas, o que Bermejo, Moraes e Graças (2010) confirmam em suas pesquisas com alunos do Ensino Médio e Licenciandos em Matemática. Embora consideramos as deduções de fórmulas interessantes para aprendizagem dos alunos, um ensino desvinculado as práticas sociais não formam cidadãos críticos e autônomos, apenas, copistas de fórmulas e conceitos matemáticos, é preciso melhorar essas concepções.

Então, para contribuir com o ensino das sequências numéricas, e consequentemente com sua aprendizagem, a incorporação da história da matemática vinculada aos materiais manipulativos, possibilita uma interação com o teórico e o prático na construção do conhecimento matemático. Com relação a história da matemática, sua importância se dá por meio da "compreensão da evolução dos conceitos enfatizando as dificuldades epistemológicas, ou seja, sua origem, estrutura, métodos e validade do conhecimento, inerentes ao conceito que está sendo trabalhado" (OLIVEIRA; OLIVEIRA; VAZ, 2014, p. 460). Já os materiais manipulativos, “está associada à manipulação aluno, atribuindo uma grande importância aos materiais didáticos, visto melhorarem a compreensão dos conteúdos de forma lúdica e possibilitarem ao aluno a construção do seu conhecimento" (BOTAS; MOREIRA, 2013, p. 273).

Dessa maneira, esse estudo tem o intuito de apresentar propostas didáticas sobre os números triangulares por meio da utilização de material manipulável envolvendo a história da matemática. Essa pesquisa está baseado em uma abordagem metodológica pautada na pesquisa documental que para Kripka, Scheller e Bonotto (2015, p. 244) o estudo documental "consiste num intenso e amplo exame de diversos materiais que ainda não sofreram nenhum trabalho de análise, ou que podem ser reexaminados, buscando-se outras interpretações ou informações complementares, chamados de documentos".

O artigo está dividido em duas partes. A primeira é uma apresentação história dos números triangulares juntamente com outras contribuições da escola pitagórica. E a segunda é uma proposta de atividade para o ensino de sequências numéricas por meios dos números triangulares.

\section{A escola pitagórica e sua contribuição para os números triangulares}

Na Grécia antiga surgiram várias escolas filosóficas, nas quais se desenvolviam muitos conhecimentos matemáticos. Uma delas, seria a escola de Tales de Mileto, mais 
conhecida como Escola Ioniana. Uma outra, seria a Escola Pitagórica que teria sido fundada por Pitágoras, e possuía vários seguidores.

A Escola Pitagórica surgiu após a queda da Escola Ioniana, Pitágoras nasceu na ilha de Samos, que é perto de Mileto, acabou conhecendo Tales e se tornando seu aluno. Com ajuda de Tales acabou aprendendo alguns conhecimentos matemáticos, e viajou para diversos lugares para aperfeiçoá-los. (MOL, 2013)

Em uma dessas viagens acabou ficando em Crotona, onde realizou algumas reuniões. Nelas envolviam pensamentos religiosos, filosóficos e científicos. Conquistando seguidores, e assim fundou o que conhecemos por Escola Pitagórica. Além de ser envolvido com o misticismo, a escola abrangia os estudos de aritmética, ou a ciência dos números. Para os frequentadores, todas coisas eram números, ou seja, os números poderiam explicar qualquer fenômeno. E o número 1 (um) era especial pois tudo se inicia por um, principalmente Deus que para eles, era simplesmente um (CONTADOR, 2015).

Percebe-se também a paixão pela música, que para Pitágoras o universo era uma escola de música. E foi através dos números que ele, "desenvolveu o estudo das notas musicais que o levou a descobrir que cordas em vibração emitem sons que dependem de seus comprimentos" (CONTADOR, 2015, p. 58). Podendo cada nota musical ser explicada por simples frações.

Dentre as várias relações entre a aritmética estudada pelos pitagóricos, e a ergometria, por exemplo, encontramos os números figurados. De acordo com Eves (2011) os números figurados expressam o número de pontos em certas configurações geométricas, representam um elo entre a geometria e a aritmética, ou seja, são pontos que ligados formam figuras geométricas (Figura 1).
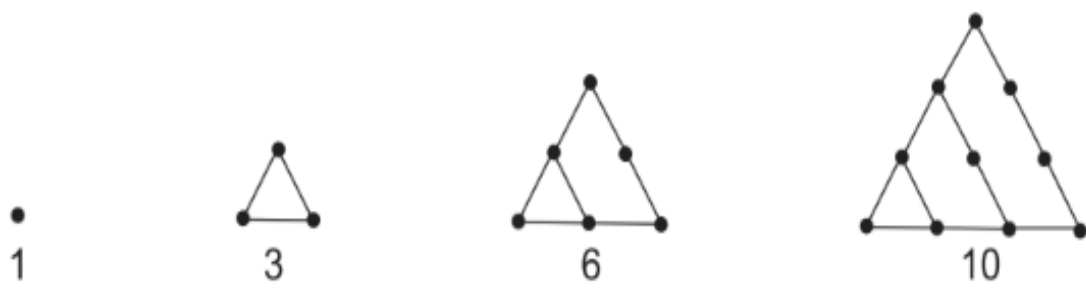

Figura 1 - Números triangulares

Fonte: Eves (2011, p. 100). 
Essa sequência de números, chamada de números triangulares, inicia-se com um ponto. Depois acrescenta-se mais dois pontos formando um triângulo equilátero, quando ligado ao ponto já existente. Do triângulo construído anteriormente, acrescenta-se mais três pontos, formando assim um triângulo maior que no total possui 6 pontos, ou seja, cada número representa a quantidades de pontos que formam triângulos equiláteros. Logo, os números triangulares são 1, 3, 6, 10, 15, e assim sucessivamente.

Além dos números triangulares, os números figurados também possuem os números quadrados (Figura 2), e os números pentagonais (Figura 3) e vários outros.

1



4



9

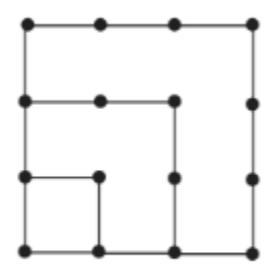

16 e assim por diante

Figura 2 - Números quadrados

Fonte: Eves (2011, p. 100).

A sequência dos números quadrados, inicia-se com um ponto, como os números triangulares, depois acrescenta-se mais três pontos formando um quadrado, quando ligado ao ponto já existente.

Do quadrado construído anteriormente, acrescenta-se mais cinco pontos, formando assim um quadrado maior que no total possui 9 pontos. E depois no quadrado de 9 pontos, acrescenta-se mais 7 pontos. Ou seja, vai sempre acrescentando o próximo número ímpar. Da seguinte maneira: $\mathrm{Q}_{1}=1 ; \mathrm{Q}_{2}=1+3=4 ; \mathrm{Q}_{3}=1+3+5=9 ; \ldots$ e assim sucessivamente.

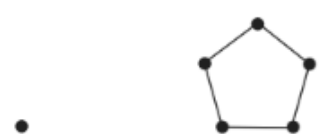

1

5

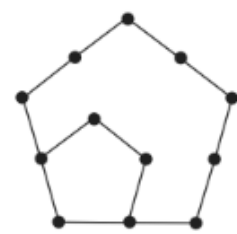

12

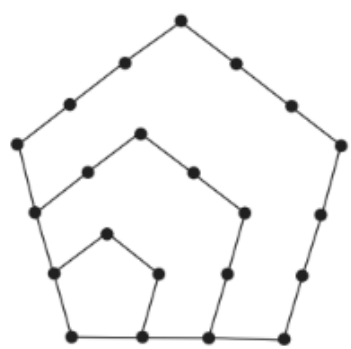

22 e assim

por diante

Figura 3 - Números pentagonais

Fonte: Eves (2011, p.101). 
A sequência dos números pentagonais, inicia-se com um ponto, da mesma forma das sequências anteriores. Depois acrescenta-se mais quatro pontos formando um pentágono, quando ligado ao ponto já existente.

Do pentágono construído anteriormente, acrescenta-se mais sete pontos, formando assim um pentágono maior, que no total possui 12 pontos. E depois no pentágono de 12 pontos, acrescenta-se mais 10 pontos, formando assim um pentágono de 22 pontos. A construção realizada da seguinte maneira: $\mathrm{P}_{1}=1 ; \mathrm{P}_{2}=1+4=5 \mathrm{P}_{3}=1+4+7$ $=12 ; \mathrm{P}_{4}=1+4+7+10=22 ; \ldots$ e assim sucessivamente.

Essas três sequências numéricas que envolve figuras geométricas com a aritmética não são as únicas existentes. Porém, iremos apresentar nesse estudo, apenas as três primeiras sequências, pois estamos interessados em estudar os números triangulares.

\title{
3. Propostas didáticas para o ensino de sequências numéricas por meio dos números triangulares
}

Durante o estudo, foram desenvolvidas duas propostas didáticas que se complementam. A primeira será voltada para história da matemática, especificamente sobre a escola pitagórica e suas contribuições para os números triangulares e a segunda envolve o uso de material manipulativo para o ensino de sequências numéricas.

Para um melhor desenvolvimento dessas propostas, utilizamos metodologia que envolve as Atividades Orientadoras de Ensino (AOE), pois:

\begin{abstract}
$\mathrm{Na} \mathrm{AOE}$, ambos, professor e aluno, são sujeitos em atividade e como sujeitos se constituem como indivíduos portadores de conhecimentos, valores e afetividade que estarão presentes no modo como realizarão as ações que têm por objetivo um conhecimento de qualidade nova. Tomar consciência de que sujeitos em atividade são indivíduos é primordial para considerar a Atividade Orientadora de Ensino como um processo de aproximação constante do objeto: o conhecimento de qualidade nova. A atividade, assim, só pode ser orientadora. Nesse sentido, a AOE toma a dimensão de mediação ao se constituir como um modo de realização de ensino e de aprendizagem dos sujeitos que, ao agirem num espaço da aprendizagem, se modificam e assim também se constituirão em sujeitos de qualidade nova. (MOURA; ARANJO; MORETTI; 2010, p. 218)
\end{abstract}

É importante utilizar AOE como metodologia, porque além do professor o aluno precisa ser portador de conhecimento. Já que ele irá construir seu próprio conhecimento 
manipulando materiais, ou lendo sobre a história da matemática. Desta forma, ele chegará ao objetivo que é o conhecimento de qualidade nova, através da atividade orientadora.

A seguir, será apresentado as propostas didáticas estão voltadas aos alunos do ensino médio, tendo como principal objetivo a identificação, a investigação, e a aprendizagem sobre os números triangulares, através da competência específica 5 da BNCC.

\section{Proposta 1: Os números triangulares e os pitagóricos}

Essa atividade está orientada para alunos do 10 ano do Ensino Médio e tem como objetivo identificar e conhecer os números triangulares através da história dos números figurados. Ela está vinculada a habilidade proposta na BNCC (BRASIL, 2018, p. 533): "investigar propriedades de figuras geométricas, questionando suas conjecturas por meio da busca de contraexemplos, para refutá-las ou reconhecer a necessidade de sua demonstração para validação, como os teoremas relativos aos quadriláteros e triângulos".

Com relação aos materiais utilizados na atividade, o professor deve ter: projetor, caixa de som e um computador para reprodução de um vídeo, além de cópias do texto que se remeta a escola pitagórica e sua contribuição para os números triangulares.

Inicialmente o professor deve identificar os conhecimentos prévios dos alunos sobre a escola pitagórica. Provavelmente, os alunos irão comentar sobre o teorema de Pitágoras. Então, essa será a oportunidade de expor o vídeo (Figura 4) sobre os pitagóricos.

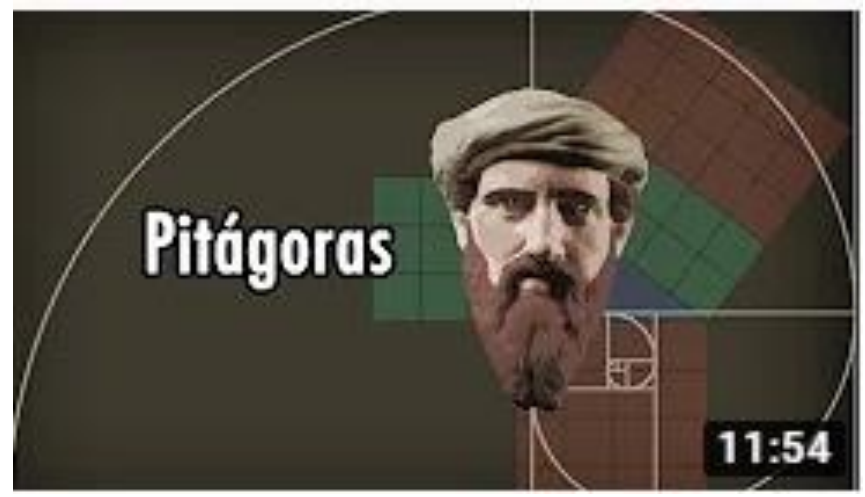

Figura 4 - Vídeo sobre Pitágoras

Fonte: Conhecimentos da humanidade (2016). 
Posteriormente o professor deve dividir a turma em equipes de 4 pessoas, estimulando as funções e os tópicos do texto para cada uma delas. Ao final do tempo estipulado para leitura do texto e para partilha de conhecimentos entre os membros das equipes, o professor irá avaliar por meio de perguntas realizadas as equipes e suas apresentações sobre o assunto estudado.

Assim, essa atividade contribuirá para a introdução da sequência numérica, associadas a algumas tendências da educação matemática como: o uso da história da matemática numa vertente mais tradicional ${ }^{4}$, e a utilização de Tecnologias da Informação e Comunicação (TIC), em particular o emprego do vídeo.

\section{Etapa 2: Contruindo números triangulares com material manipulável}

Essa atividade está orientada para alunos do $1^{\underline{0}}$ ano do ensino Médio e têm os seguintes objetivos a serem alcançados no decorrer da atividade: entender a construção dos quatro primeiros termos dos números triangulares com materiais manipuláveis; identificar o próximo termo da sequência dos números triangulares; apresentar e descrever o processo gerador dos termos encontrados da sequência dos números triangulares; definir com suas palavras, uma sequência numérica, após trabalhar com os números triangulares. Ela está vinculada as habilidades propostas na BNCC (BRASIL, 2018, p. 533):

(EM13MAT512) Investigar propriedades de figuras geométricas, questionando suas conjecturas por meio da busca de contraexemplos, para refutá-las ou reconhecer a necessidade de sua demonstração para validação, como os teoremas relativos aos quadriláteros e triângulos.

(EM13MAT507) Identificar e associar sequências numéricas (PA) a funções afins de domínios discretos para análise de propriedades, incluindo dedução de algumas fórmulas e resolução de problemas.

Com relação aos materiais utilizados na atividade, o professor deve ter: um questionário, no qual será descrito posteriormente, 28 tampinhas de garrafas no mínimo para cada equipe de 4 alunos, e se necessário giz para riscar o chão. Ele deve informar aos alunos sobre esse material uma semana antes da atividade, para serem providenciadas pelos membros das equipes.

\footnotetext{
${ }^{4}$ Segundo Pereira e Saito $(2018$, p. 3) a vertente historiográfica tradicional “o pensamento matemático é entendido como uma sucessão de descobertas que beneficiam exclusivamente concepções internas a própria matemática. Dessa forma, o pesquisador está interessado nas narrativas do presente.”
} 
Inicialmente o professor deve apresentar a sequência dos quatro primeiros termos dos números triangulares com material manipulável. Da seguinte forma, primeiramente colocando uma tampinha sozinha no chão, representando o primeiro termo da sequência.

Depois é alocando mais duas tampinhas abaixo da primeira, de tal forma que ao ligar as tampinhas com o giz, forme um triângulo equilátero (Figura 5). Com isso, teremos na formação do triângulo três tampinhas, ou seja, o segundo termo da sequência é três.

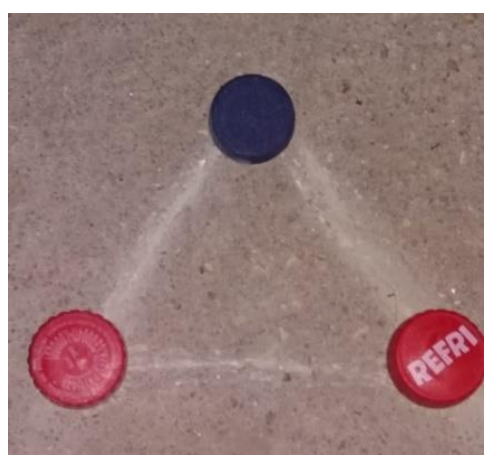

Figura 5 - Construção do segundo termos dos números triangulares.

Fonte: Elaborada pela autora (2019).

Agora, abaixo das duas tampinhas colocadas anteriormente. Ele colocará mais três, de tal forma que consiga desenhar com o giz um novo triangulo equilátero, que desta vez possuirá seis tampinhas (Figura 6). Assim, contando a quantidade de tampinhas utilizada nesse novo triângulo, encontraremos o terceiro termo que é seis.

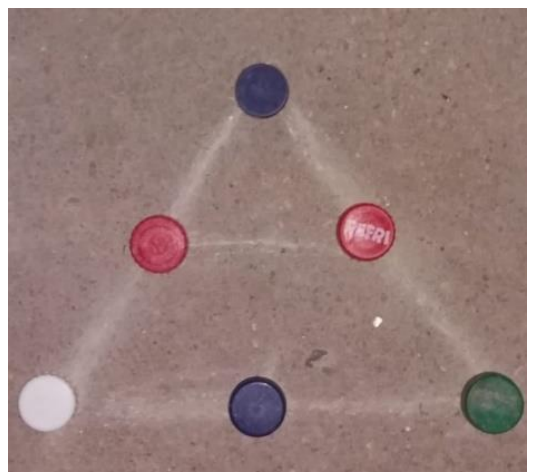

Figura 6 - Construção do terceiro termos dos números triangulares.

Fonte: Elaborada pela autora (2019)

No próximo, ele colocará quatro tampinhas abaixo das três colocadas anteriormente. E da mesma maneira desenhará um novo triângulo equilátero, que possuirá 
agora dez tampinhas (Figura 7). Como o novo triângulo possui dez tampinhas, então o quarto termo é dez.

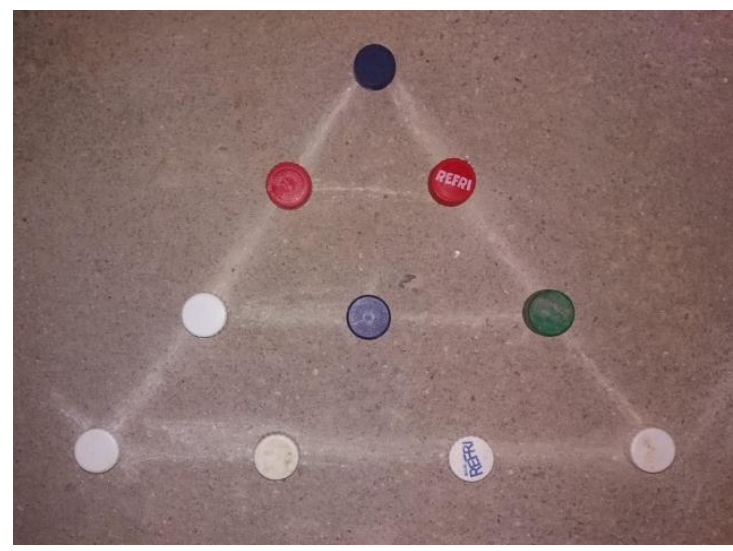

Figura 7 - Construção dos quatro primeiros termos dos números triangulares.

Fonte: Elaborado pela autora (2019)

Posteriormente ele deve dividir os alunos em equipes de quatro pessoas, e cada equipe deve ter no mínimo 28 oito tampas para manipulação e um giz, se necessário. $\mathrm{O}$ docente deve distribuir para cada equipe o seguinte questionário:

1. Sabendo que o $1^{\circ}$ termo dos números triangulares é 1 , e o $2^{\circ}$ termo é 3 , qual é o $3^{\circ}$ termo? Justifique sua resposta utilizando o material manipulável e descreva os passos.

2. Qual é o $4^{\circ}$ termo? Justifique sua resposta utilizando o material manipulável e descreva os passos.

3. Qual é o $5^{\circ}$ termo? Justifique sua resposta utilizando o material manipulável e descreva os passos.

4. Qual é o $6^{\circ}$ termo? Justifique sua resposta utilizando o material manipulável e descreva os passos.

5. Qual é o $7^{\circ}$ termo? Justifique sua resposta utilizando o material manipulável e descreva os passos.

6. Agora que encontrou os sete primeiros termos da sequência, descreva qual foi a lógica utilizada para encontrar cada termo.

7. Quantos termos possui a sequência dos números triangulares? Justifique.

8. Após toda a manipulação dos números triangulares. Defina uma sequência com suas palavras. 
9. Na sua opinião, tem como construir uma fórmula para encontrar cada elemento dos números triangulares? Justifique.

DESAFIO: Desenvolva a fórmula para encontrar cada termo da sequência dos números triangulares.

As cinco primeiras perguntas farão com que os alunos utilizem o material manipulável. Assim, eles poderão construir cada termo da sequência e mesmo que ele não consiga enxergar a lógica da construção dos termos, através da descrição eles conseguirão identificá-las.

Para responder à questão 6, basta os alunos lerem suas respostas anteriores, analisando qual foi a lógica da construção de cada termo. Se os alunos, estiverem entendidos a construção de cada termo, não será necessário ler suas anteriores, pois eles conseguirão responder à pergunta facilmente.

A questão 7 tem um objetivo de identificar, se os alunos conseguem perceber que existe uma infinidade de números triangulares, ou seja, através dessa pergunta o aluno terá uma ideia de infinito. Agora, depois de toda essa manipulação dos números triangulares, os alunos podem pensar na questão 8 e 9.

As questões 8 e 9, são diferentes das outras, porque as outras davam para responder apenas observando e entendo a manipulação do material, porém, essas duas questões precisão que os alunos pensem um pouco mais e tente construir suas respostas. E as serão finalizadas com o desafio, que será opcional para os alunos.

E finalmente, o professor pedirá para um representante de cada grupo, fazer uma apresentação sobre os conhecimentos adquiridos. Podendo ou não utilizar o questionário respondido, com o material manipulável. Porém, todas as equipes têm que definir uma sequência após a utilização dos números triangulares.

Assim, após toda essa descrição podemos observar alguns conteúdos que serão utilizados nessa atividade, tais como, propriedades de triângulos, especificamente dos triângulos equiláteros que eles construirão com o material manipulável; noções de infinito, na análise que existem infinitos números triangulares; e não podemos esquecer da lógica, que eles utilizaram para construção.

A avaliação será realizada, no decorrer da utilização do material manipulável e pode ser a apresentação dos representantes de cada grupo. Além da resolução do 
questionário, que se encontra as perguntas relacionadas aos objetivos, assim o professor consegue avaliar se os alunos alcançaram ou não.

\section{Considerações Finais}

Esse artigo apresenta propostas de atividades para o ensino sequência numérica por meio dos números triangulares, no qual foram propostas duas atividades, uma utilizando a história dos números triangulares, e a outra utilizando material manipulável.

Dentre os vários aspectos que nos motivaram para a realização deste estudo, um que chamou atenção foi a dificuldade dos alunos na compreensão dos conceitos envolvendo sequência numérica, em particular, quando se estuda ela no infinito, pois eles não conseguem visualizar matematicamente essa sequência.

Assim, devido a esta dificuldade, nos empenhamos em elaborar atividades que pudessem fazer com que o aluno manipule, e entenda sequência numérica relacionado ao infinito e através da história consiga observar sua importância.

A principal perspectiva desse estudo, seria aplicação dessas atividades em alunos do Ensino Médio, para assim levantar dados para serem analisados, em relação a aceitação da atividade pelos alunos. Outras perspectivas seria, utilizar os números triangulares no estudo de outros assuntos, ou, fazer uma pesquisa voltada aos possíveis estudos de conteúdos que podem utilizar os números triangulares, como meio de ensino.

\section{Referências}

BERMEJO, Ana Priscila Borges; MORAES, Mônica Suelen Ferreira de; GRAÇA, Vagner Viana da. Análise das dificuldades do ensino de progressões. In: ENCONTRO PARAENSE DE EDUCAÇÃO MATEMÁTICA, 7., 2010, Belém. Anais [...] . Belém: Sbem, 2010. p. 1 - 17.

BOTAS, Dilaila; MOREIRA, Darlinda. A utilização dos materiais didáticos nas aulas de Matemática - Um estudo no $1^{\circ}$ Ciclo. Revista Portuguesa de Educação, Braga, v. 26, n. 1, p.253-286, mar. 2013.

BRASIL. Base Nacional Comum Curricular. Brasília: MEC, 2017.

BRASIL. Secretaria de Educação Média e Tecnológica. Parâmetros curriculares nacionais (Ensino Médio) - Linguagens, Códigos e suas Tecnologias. Brasília, 2000.

CONTADOR, Paulo Roberto Martins. A matemática na arte e na vida. São Paulo: Editora Livraria da Física, 2015. 
EVES, Howard. Introdução à história da matemática. Campinas: Unicamp, 2011.

KRIPKA, Rosana Maria Luvezute; SCHELLER, Morgana; BONOTTO, Danusa de Lara. Pesquisa Documental: considerações sobre conceitos e características na Pesquisa Qualitativa. Atas - Investigação Qualitativa na Educação, Porto Alegre, v. 2, p.243247, 21 jul. 2015.

MOL, Rogério S.. Introdução à História da Matemática. Belo Horizonte: CAEDUFMG, 2013.

MOURA, Manoel Oriosvaldo de; ARANJO, Elaine Sampaio; MORETTI, Vanessa Dias; Panossian, Maria Lúcia; Ribeiro, Flávia Dias. Atividade Orientadora de Ensino: unidade entre ensino e aprendizagem. Diálogo Educação, Curitiba, v. 10, n. 29, p.205229, jan./abr. 2010.

OLIVEIRA, Vanessa Castro de; OLIVEIRA, Cristiano Peres; VAZ, Francieli Aparecida. a história da matemática e o processo de ensino aprendizagem. In: EREMAT -ENCONTRO REGIONAL DE ESTUDANTES DE MATEMÁTICA DA REGIÃOSUL, 20., 2014, Bagé. Anais [...] . Bagé: Unipampa, 2014. p. 1 - 4.

PEREIRA, Ana Carolina Costa; SAITO, Fumikazu. Os instrumentos matemáticos na interface entre história e ensino de matemática: compreendendo o cenário nacional nos últimos 10 anos. : compreendendo o cenário nacional nos últimos 10 anos. Boletim Cearense de Educação e História da Matemática, Fortaleza, v. 4, n. 11, p. 1-12, ago. 2018. 